\title{
Explanatory Power of Selected Proxies in Predicting Stock Returns of Large U.K. Companies
}

\author{
Daniel F. Rodriguez ${ }^{1}$, Ali Malik ${ }^{2}$, Nasser I. Abumustafa ${ }^{2} \&$ Arshad Jamal $^{1}$ \\ ${ }^{1}$ Northumbria University, London Campus, UK \\ ${ }^{2}$ QFBA - Northumbria University, Doha, Qatar \\ Correspondence: Ali Malik, QFBA - Northumbria University, Doha, Qatar. E-mail: malik@Northumbria.edu.qa
}

Received: January 31, 2019

Accepted: February 22, 2019

Online Published: March 8, 2019

doi:10.5539/ijbm.v14n4p72

URL: https://doi.org/10.5539/ijbm.v14n4p72

\begin{abstract}
Predicting stock returns has been instrumental in our understanding of capital market structure. The validity of models, like the Capital Asset Pricing Model or the Gordon Growth Model, has influenced and contributed to building mathematical representations in predicting required return. Several studies attempted to explore different variables to determine the explanatory power of proxies in predicting stock return. For example, it is reported that dividends can explain up to $25 \%$ of the variance in returns. The explanatory power of dividends in the regression analysis showed a significant variation when the analysis follows time-series methodology. This study aims at examining the predicting power in the U.K. equity market by plugging into the regression model some of the variables conventionally measured in the Structural Equation Modeling. The study is quantitative and uses secondary data. The findings of this study suggest that the selected proxies, dividend growth, earnings per share, and beta exhibit weak explanatory power in predicting returns of large U.K. companies.
\end{abstract}

Keywords: earnings per share, dividend growth, coefficient beta, stock return

\section{Introduction}

The paper contributes to on-going debate on the possibility of predicting stock returns. The research area is rich and there exists a voluminous literature on it. The issue, however, is far from settled and continues to attract new researchers who strive to develop models and techniques to outperform the market. The motivation of this research comes from the understanding developed on existing literature evidence that it would be highly useful and relevant to examine the returns predictability in the U.K. equity market by plugging into the regression some of the variables conventionally measured in the Structural Equation Modeling (SEM). The study is the first attempt to examine this for large UK companies by not performing the Structural Equation Modelling but plugging into simple and multiple regression analysis some the latent variables conventionally used in the SEM. The research framework and findings are likely to be of interest and will encourage further investigation into plugging together isolated indicators to determine proxy power of predicting stock returns.

The analysis of Structural Equation Modelling (SEM) is used to establish a more integrated view of the relationship of variables, in which the correlation of latent variables and indicators can be measured. In the analysis of SEM, the predictability of stock return is built upon three factors that resolve the explanatory power. According to Anhar (2015), these factors can be used to predict stock return in the analysis of SEM. The first factor is company performance and its indicators are: earnings per share (EPS), price-earnings ratio (PER), book value $(\mathrm{BV})$, price-book value ratio (PBV), debt-equity ratio (DER), return on assets (ROA), return on equity (ROE), and net profit margin (NPM). The second factor is investor expectations, and its indicators are: price trend, latest return, average return, return trend, latest return percentage, average return percentage, and return trend percentage (PT, LR, AR, RT, LR\%, AR\% and $\mathrm{RT} \%$ ). The third factor is the investment risk and its indicators are: standard deviation of return, coefficient of variation, and coefficient beta of stock (SD, CV and Beta).

It is not intended to perform Structural Equation Modeling analysis, we rather examine some of the indicators selected and to evaluate the explanatory power using simple and multiple regression analysis. The factors are assumed as latent variables used in the analysis of Structural Equation Modelling (SEM). The indicators subject to the model in this paper are earnings per share (PER), beta value $(\beta)$ and dividend growth (DG). 


\section{Literature Review}

\subsection{The Classical Approach to Efficiency}

There is a growing body of literature that recognizes the importance of market efficiency theory in testing the ability to find abnormal returns. According to Fama (1991), there are three forms of efficient market hypothesis (EMH): weak, semi-strong, and strong. Empirical tests have focused on the weak form of efficiency, concluding that it is not possible to predict future stock prices based on past information. Most of these studies implemented the stochastic approach, meaning that they focused on the use of random probability distribution (Lean \& Smyth, 2015).

For investment opportunities, many strands of literature focused on company performance ratios, such as the market-to-book ratio. In general, the market-to-book ratio has been a significant proxy in stock returns. According to Detzel and Strauss (2017), this ratio provides an indication of future cash flows in present value. Their findings showed that a cross-section of the industry book-to-market values has mere explanatory power using a combination of quarterly forecast returns.

Another proposition to examine future investment opportunities is related to the price-earnings ratio (PER), indicating the ratio of market value of equity and present earnings. As stated by Pietrovito (2016), the PER ratio does add value to the investment rates when it is included in the Tobin's q model. It is incorporated in a model of regression to determine the explanatory power of investment rate, giving a positive relation for the predictive model.

Tobin's q model equation:

$$
y_{i t}=\alpha y_{i(t-1)}+\beta X_{i t}+v_{i}+v_{t}+v_{j}+e_{i t}
$$

In Tobin's q model the $y_{i t}$ is the average for market to book ratio explained by its replacement cost, the $X_{\mathrm{it}}$ are the independent variables, $e_{i t}$ is the error term in the regression model, and $v_{i}, v_{t}, v_{j}$ values are dummy variables to control exogenous variables as industry effects.

\subsection{Investment Risk}

In functional markets, all managers and investors are rewarded when welcoming the high risks associated with investing in assets. Risk is also referred to as 'risk factors' (Besley and Brigham, 2006). Systematic risk is measured by evaluating the movement of the return trend of a company stock to follow the movement of the stock market return, and its size is the beta coefficient ( $\beta$ ) of stock (Besley and Brigham, 2006, p. 34)

Some analysts, like Setiono and Strong (1998), attempted to draw fine distinctions between markets in many countries, which are semi-strong form, efficient finding, and predicting abnormal stock returns with publicly available financial statements. Some earlier observed reports indicated that, to some degree, future earnings can be predicted from current and past incomes and that current stock prices reflect inexperienced expectations of earnings.

Linear predictive regression is an increasingly important area in applied market studies. Some earlier studies used the techniques of time-series or cross section analysis to explain market beta in expected returns (Fama and French, 2004). Such techniques can also be applied, as proposed by Bekiros and Gupta (2015), using a linear predictive regression model with different indicators to predict stock market returns in monthly sequences. Difficulties arose, however, when attempts were made to implement this model to predict volatility. This encouraged more focused studies, such as mixes of other tests to examine real returns and their link to investor sentiment indexes.

According to Choudhary and Choudhary (2010), testing the Capital Asset Pricing Model (CAPM) should be performed by modifying the conventional formula. CAPM is tested with a regression of security return for beta value where the intercept is the difference between estimate of the expected return and the actual CAPM return.

The model of regression analysis for CAPM is:

$$
r_{j}-R f=\propto i \beta i x r_{m}-R f+\varepsilon_{j}
$$

where $R f$ is risk-free return, $r_{j}$ is required return on investment, $r_{m}$ is expected market value of return, $\beta$ is beta (risk), $\varepsilon_{j}$ is the disturbance term or error, and $\propto$ is the intercept.

There is evidence of a positive relation between beta and stock return in the case where the difference between market value of the stock and the risk-free return is greater than zero.

The validity of CAPM has been repeatedly tested. To some extent, the earlier studies are responsible for simplifying the model of the analysis. Researchers, such as Sharpe (1964) and Lintner (1965), suggested that the 
risk-free rate of return is the intercept of the equation, and the difference between expected market return and risk-free rate will always be the slope. These assumptions result in a flat outcome when measuring the relationship between return and beta (Miller \& Scholes, 1972).

Conventionally, dividend yield has a strong predictive power on stock return; however, Ang and Bekaert (2007) reported that dividend yield has explanatory power only for short time horizons. Campbell and Yogo (2006) found a strong predictive power for short rates rather than long periods. All the components from the dividend growth model are generally seen as indicators strongly related to return prediction. Some of the literature has focused on the relationship between dividend yield and earnings growth. As stated by Kothari and Shanken (1992), since the empirical argument shows that dividend constrains funds for future investments, it tends to have a negative impact on earnings growth. This argument contradicts Zhou and Ruland (2006), who found a strong relationship between the two variables.

The model developed by Kothari and Shanken (1992) to predict Swedish stock return from dividend yield and dividend growth showed a rather weak explanatory power. It measured the natural log of the continuous compounded ratio from the dividend $D_{t}$ in year $t$ and the dividend in year $t-1 . D G=\operatorname{Ln}\left(D_{t} / D_{(t-1)}\right), F G D=$ $\operatorname{Ln}\left(D_{t} / D_{(t+k-1)}\right)$, for the year $t+k$. where $D G$ is the dividend growth, $F D G$ is the dividend growth at the time $T+$ $K-1$. The model also included a dividend to price ratio (D/P), Nordic 40 index (RNAS), and the productivity growth index (PGI). After all the proxies are established the model takes the form:

$$
R i=\alpha+\lambda_{0} D G+\sum_{k=1}^{3} \lambda \lambda_{k} F G D_{k}+\lambda_{k+1} D / P+\lambda_{k+2} R N A S+\lambda_{k+3} P G I+\varepsilon i
$$

Where the dependent variable $R_{i}$ is the return on equal weighted portfolio from the NASDAQ OMX index from Stockholm.

The result of the study showed a weak relationship between dividend yield and dividend growth when measured only with the dividend proxies shown in the equation. However, the explanatory power of the model increases its $R^{2}$ when using the U.S. equity market (NYSE), indicating strong aggregate stock returns in the case of Swedish stocks.

\subsection{Investors' Expectation}

The expectation of an investment is related to the evaluation of a certain trading security and its future trend. Most of the indicators associated with investor expectations are defined by technical analyses that focus on the history of stock actions in order to predict future movements. Investor expectation can be outlined by price trend, latest return, average return, return trend, latest return percentage, average return percentage, and return trend percentage (Anhar, 2015).

In technical analysis, the research leads to decisions on using linear and nonlinear methods. Enders and Pascalau (2015) tested the linearity of real exchange rates using the smooth transition autoregressive (STAR) model and found that, when rejecting the null hypothesis of a linear model, the forecast will result in low mean square prediction errors. By not rejecting the linearity, the nonlinear model also produces low mean square prediction errors and will beat the random walk forecast. It seems that, according to Enders and Pascalau (2015), the nonlinear methods in technical analysis produce a superior predictive forecast.

Sheela and Murugesan (2017) stated that daily return predictability for nonlinear models provide better captured information of the behavior on daily stocks' returns. It then improves the accuracy of forecasting for short term horizons, even more so than linear models.

Whereas fundamental analysis focuses on the influence of other proxies, such as dividend yield, earnings, and insider trading, technical analysis relies on the premise that stocks already have all this information and absorb new data automatically (Gong and Sun, 2009). The factor that explains trading movements is the sentiment of the investor responses to changes, showing enough patterns and historical trends to provide prediction power (Murphy and Murphy, 1999). It is not the intention of this research to explore technical analysis; however, this could be part of the recommendations for further studies, considering some of these indicators as part of further methodologies of fundamental analysis. Although, even when measuring a wide range of information, stock returns are not well explained and predicted even in the most recent and complex tests. Hou et al. (2017) found 450 anomalies in stock returns not yet clarified, even when classic approaches were used to relate these anomalies with the relative size of the investor. 


\section{Data and Methodology}

This study was designed to explore some of the indicators used to predict stock returns. Relevant results on previous studies have led to the conclusion that there is no complete and certain technique to predict returns without any biases or concerns about statistical methods, such as data mining, spurious results, or correlations between evidence and real time performance (Avramov \& Chordia, 2006). This means that there is no best-fit strategy and it is possible to find techniques better than others.

The most obvious outcome to emerge from this study is that building a critical framework to predict stock return will benefit investors who must allocate funds, but must consider many difficulties in current academic stages and mathematical techniques when considering uncertainty.

We employed $95 \%$ level of certainty and the data required to address the topic were largely the secondary data. Also, this study was designed as associative, time-series, and quantitative research to study the predictability of stock returns and create a model with different variables using the methodology of Fama and French (1992). The paper examines the stock returns of 36 large U.K. companies over the period from 2013 to 2016 in order to analyze the performance explained by means of three proxies: beta value, dividend growth, and earnings per share.

The variables in this paper consist of:

(1) Risk free rate and beta $(\beta)$

The risk-free rate of return is estimated most of the times as the government bond yield. The monthly data from U.K. for the 10 years yield were retrieved from the Bloomberg database and then the risk-free rate of return was used as one of the components of beta value. Fama and MacBeth (1973) stated that beta value is estimated by monthly returns of each stock by the following formula:

(2) Stock and market return (R)

$$
\beta i=\frac{\text { covariance } R i, R m}{\text { variance } R m}
$$

The return of stock is the continuously compounded return on equal-weighted portfolio and is calculated as the natural $\log$ of $(P / P-1)$.

$$
R i=\operatorname{Ln}(P / P-1)
$$

where $\mathrm{P}$ is the monthly closing price.

The portfolio return is built equally weighted with the following formula:

$$
R p=\sum_{i=1}^{\infty}(W i \times R i)
$$

The market value is continuously compounded return for the FTSE 100 index, where the closing monthly price $t$ is divided by the closing price in month $t-1$

$$
M R t=\operatorname{Ln}(F T S E \text { 100t/FTSE 100t-1) }
$$

(3) Dividend growth

Dividend growth is calculated by $D_{T} / D_{T-1}$ where $D$ is the dividend and is defined as the natural log of the ratio of quarterly paid dividends in month $t-1$ to quarterly paid dividends for month $t$.

(4) Earnings per share

EPS is defined as the natural $\log$ of the ratio of quarterly paid EPS in month $t-1$ to quarterly paid EPS for month $t$.

\subsection{The Regression Model}

For this paper, the independent variables $X i$ were beta value, dividend growth, and earnings per share (EPS). The regression model takes the general form:

$$
r_{t}=\alpha+\beta x_{t-1}+u_{t}
$$

For observations $\mathrm{T}_{\mathrm{j}}$, the coefficient $\beta$ is the unknown parameter of interest. When testing in a regression model, the variable $x_{t-1}$ has the ability to forecast $r_{t}$ if $\beta \neq 0$. The parameter $r_{t}$ is the stock return or the dependent variable for the modelling.

It is assumed that variables are independently and identically distributed.

\subsubsection{Step 1}

Based on Equation (1), the values for beta are calculated from the stock returns of each security and the market 
return for the period of 2013 to2016. Secondly, the return value for the 36 largest U.K. companies from the FTSE 100 were ranked from the largest to the lowest stock return values and were divided into 6 portfolios. Previous studies based their criteria for selection on portfolios. Fama and MacBeth (1973) agreed that diversification of portfolios can minimize the effect of firm-specific risk, improving the estimation of beta values and future returns.

A total of 100 firms were screened from the FTSE 100 index, from which a total of 36 companies met the sample requirement and provided weekly data of stock closing price over the study period. This produced a total of 7488 closing prices.

The first formula of the regression model was built with the parameter taken from investment risk factor, which is beta value.

$$
r_{t}=\alpha+\lambda_{1} \beta_{1}+u_{t}
$$

\subsubsection{Step 2}

It was our intention to estimate parameters using fundamental analysis with regression analysis and time-series tool techniques. The primary source of the data was FTSE 100, giving us access to the dataset for large U.K. companies from a variety of industries.

A total of 100 firms were screened from the FTSE 100 index, from which a total of 36 companies were selected that provided quarterly information of dividends. This represented a total of 576 continuously-compounded dividend growth values for month $t$. In the cases where no data were found for the dividends and earnings, we used the extrapolation technique following Fama's methodology (Fama, 1990).

The second formula for the regression model is similar to that of earlier literature on dividends explanation power on return, such as Fama and French (1998), Campbell (1991), and Kothari and Shanken (1992).

$$
r_{t}=\alpha+\lambda_{2} D G_{1}+u_{t}
$$

\subsubsection{Step 3}

EPS are the profits for a certain period of time divided by the number of outstanding shares. In this paper, the proxy used to build the model was the EPS when the companies announce the financial information every three months.

A total of 36 companies in the years 2013-2016 with quarterly earnings and dividends information qualified for the sample requirements. This represented a total of 576 quarterly earnings announcements.

EPS is defined as the natural log of the ratio of quarterly paid EPS in month $t-1$ to quarterly paid earnings per share EPS for month $t$.

$$
r_{t}=\alpha+\lambda_{3} E P S_{1}+u_{t}
$$

Regression analysis was applied to test the effect of explanatory factors and to assess the correlation of the independent variables.

After including all proxies, the model was formed as follows:

$$
r_{t}=\alpha+\lambda_{1} \beta_{1}+\lambda_{2} D G_{1}+\lambda_{3} E P S_{1}+u_{t}
$$

The proportion of variance due to the dependent variable was explained by $R^{2}$ or the coefficient of determination. $R^{2}$ indicates the squared correlation between an independent variable and predictions made by the regression of the dependent variables (Kothari and Shanken, 1992).

\subsection{Hypothesis}

The result of the test was used to interpret the relationship between beta and return.

In order to test if coefficient $\beta_{1}$ is significantly different from zero, the following hypothesis was formulated:

$H_{o}=\lambda_{1}=0$

$H_{a}=\lambda_{1} \neq 0$

The joint hypothesis was considered to summarize the variation in the total independent variables, and the ANOVA $f$ test assesses the fitness of the regression model as a group. Here, the adjusted $R^{2}$ statistic was used to explain the relationship of this group of independent variables with return.

$H_{o}=\lambda_{1}=\lambda_{2}=\lambda_{3}=0$

$H_{a}=$ At least one of the coefficients is $\neq 0$ 


\section{Results and Findings}

The regression graph in Figure 1 shows the relationship between beta and return during the years from 2013 to 2016 for 36 large U.K. companies selected randomly from FTSE 100.

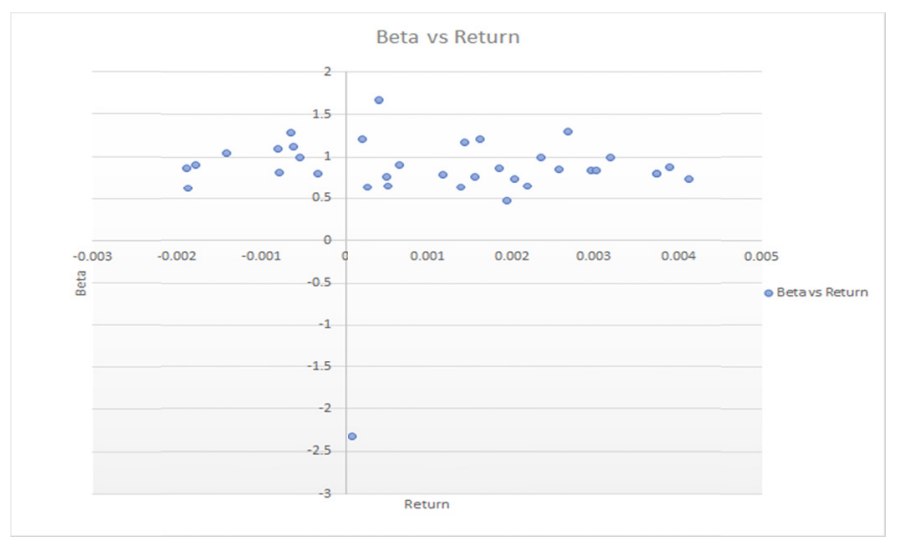

Figure 1. Average beta and return, 2013-2016

According to Figure 1, there is a positive relation between returns and beta. There is also a strong correlation between the two variables, showing a narrowly spread dots over the 48-month period. It seems that a higher beta is associated with higher return. Only one observation was an outlier, with a -2.3 corresponding to RSA Insurance Group, which had flat equal returns.

The regression graph in Figure 2 shows the relationship between dividend growth and stock return during 20132016 for the sample of 36 U.K. companies.

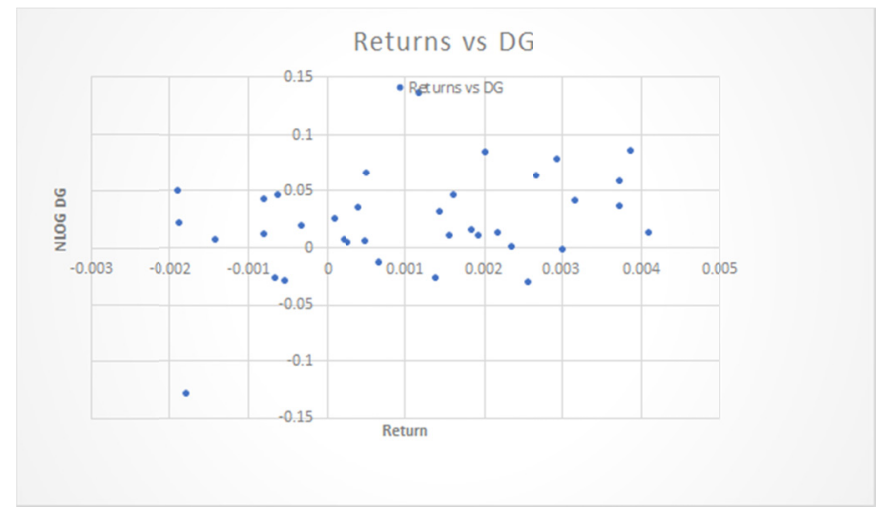

Figure 2. Dividend growth and return, 2013-2016

According to Figure 2, there is a positive relationship between returns and dividend growth except for a few outliers. There was also a relatively moderate correlation showing a wider spread of dots in the 48 months. The slope of the relationship seems to be positive, indicating higher dividends growth with higher returns. The above can be related to previous literature showing otherwise negative relationships. One possible explanation for negative relationships is that companies, in order to increase shareholder wealth, encourage cuts in dividends policies to invest the money in profitable projects.

The company performance represented in earnings per share is associated with individual security return as shown in the regression graph in Figure 3. 


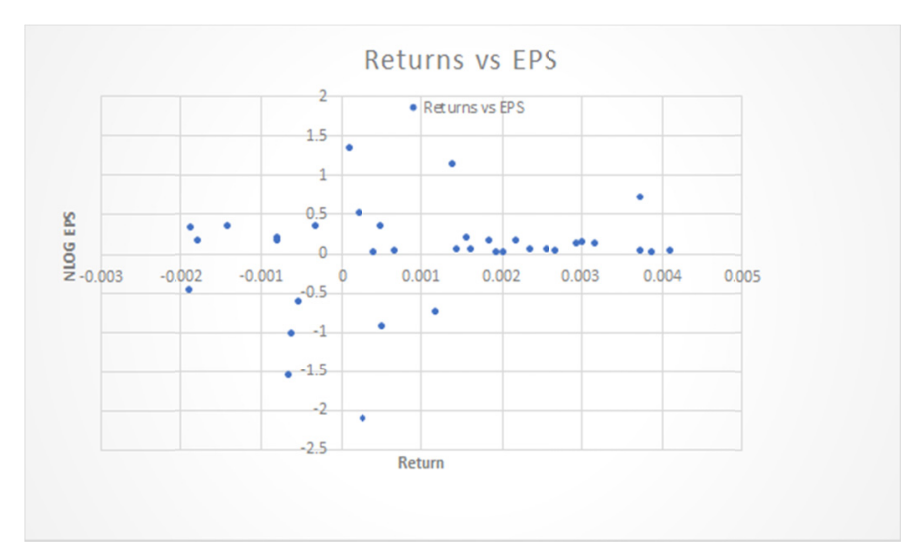

Figure 3. Earnings and returns, 2013-2016

Figure 3, which presents the average monthly return with the announcement of earnings per share, shows an upward and downward drift for about half of the observations but also a strong correlation for the other half, showing a concentrated group of dots. Some interpretation for the positive correlation between return and EPS for some of the companies is that new information on earnings may result in a good review of the original expectations of securities (Basu, 1975). However, in order to examine this, we further analyzed the portfolios with the highest and lowest returns to evaluate the relationship with earnings per share.

Figure 4 depicts time-series values for weekly compounded stock returns and market return. The values lie almost in the same line, implying a very close relationship for equally weighted portfollios. Table 1 shows the correlation matrix performed between continuously compounded returns against the respective proxies. Beta values are almost perfectly correlated to returns, with a small $P$ value, which shows correlation is significantly different from zero. However, none of the other variables were correlated with return.

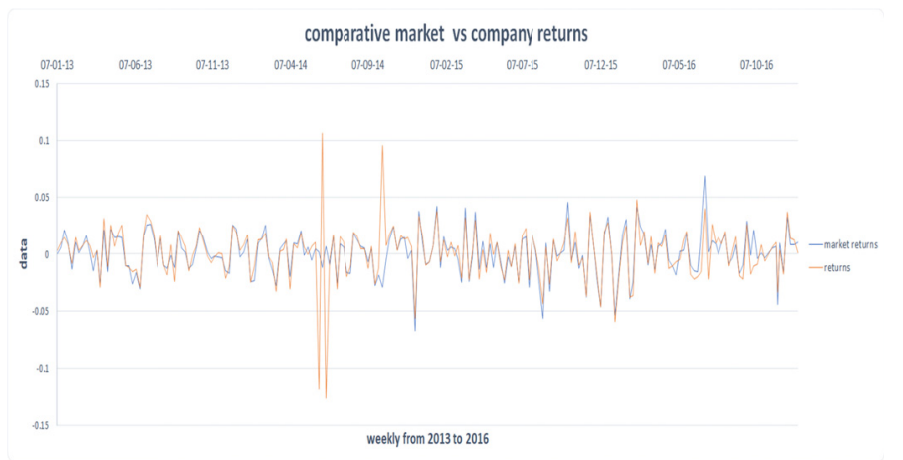

Figure 4. Time-series plot for return and market return of FTSE 100 index, 2013-2016 
Table 1. Correlation matrix of returns, DG, EPS, and beta

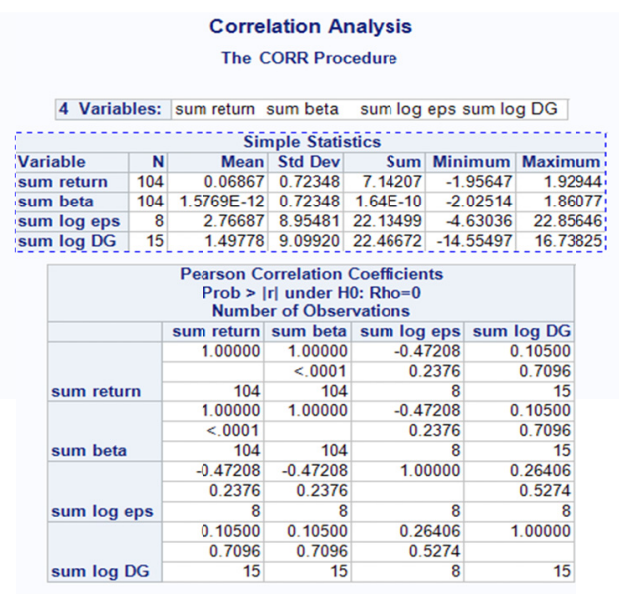

Figure 5 shows that there is a weak relationship between earnings per share and dividend growth. This observation supports the wide distance between dividend growth and earnings per share showing an opposite trend. Also, as indicated in the correlation analysis, there was no significant correlation between independent variables.

According to previous research, a possible argument for the low correlation between returns and dividend yields or dividends growth is that the last one has "the ability of tracking time-varying property of expected returns: (Kothari \& Shanken, 1992).

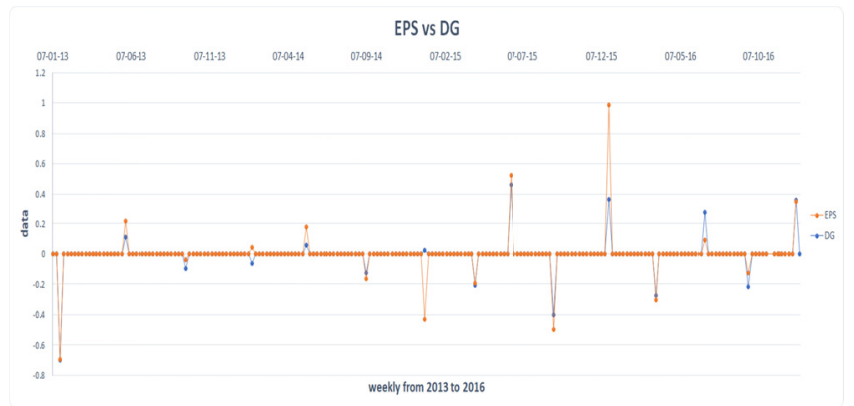

Figure 5. Time-series values between EPS and DG, 2013-2016

The $\mathrm{Y}$ axis represents the weekly data collected from the companies regarding earnings per share and dividend growth.

\subsection{Portfolio Values}

This section describes the relationship between returns and the rest of the covariates for the six portfolios formed from the sample of 36 companies selected from FTSE100. As indicated previously, 36 companies were selected meeting all the criteria to build the data and were divided into six portfolios in order to examine the data using regression analysis. This is denoted as portfolio A, B, C, D, E and F.

In order to analyze the six portfolios, the first step was to summarize the portfolio compounded returns for stock prices, beta values, earnings per share, and dividend growth. The next step was to plot the independent variable against the stock return. We found that Portfolio A had the highest returns, whereas Portfolio F had the lowest returns.

Figure 6 shows the relationship between stock returns and the beta values of the six portfolios calculated with Equation (1). 


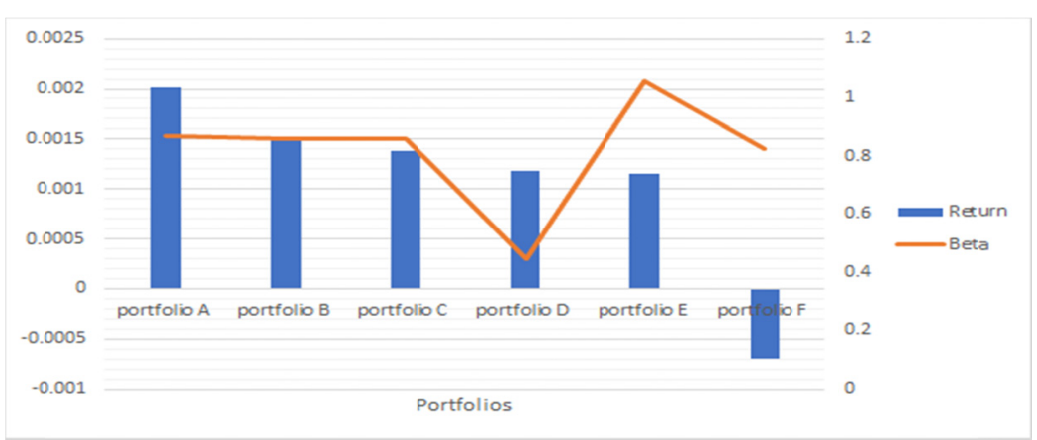

Figure 6. Portfolios return and beta, 2015-2016

Although the time-series data in Figure 4 shows a close relationship and correlation between returns and market values, Figure 6 demonstrates a negative relationship in portfolios with lower returns with respect to beta values. This reminds us that companies with lower returns tend to have higher systematic risk. Other variables could merge into the relationship depending on the industrial sector. For example, big utility companies should have a lower beta, whereas tech companies can bounces stocks up and down with considerable volatility.

Figure 7 shows the relationship between portfolio returns and the EPS of the six portfolios calculated with logarithmic returns.

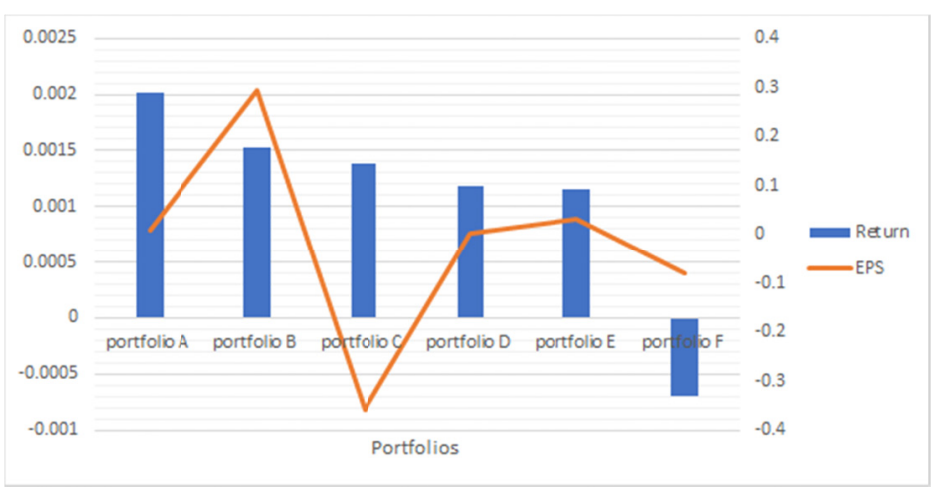

Figure 7. Portfolios return and EPS, 2013-2016

Although the graph shows a weak correlation between variables, many of the values are negative even when returns are highly positive with respect to the period in Portfolio $\mathrm{C}$. The evaluation of the correlation is also not strong, considering the smaller amount data for earnings and dividends compared with the data for closing prices.

Figure 8 shows the relationship between stock returns vs. DG for the six portfolios calculated with logarithmic returns.

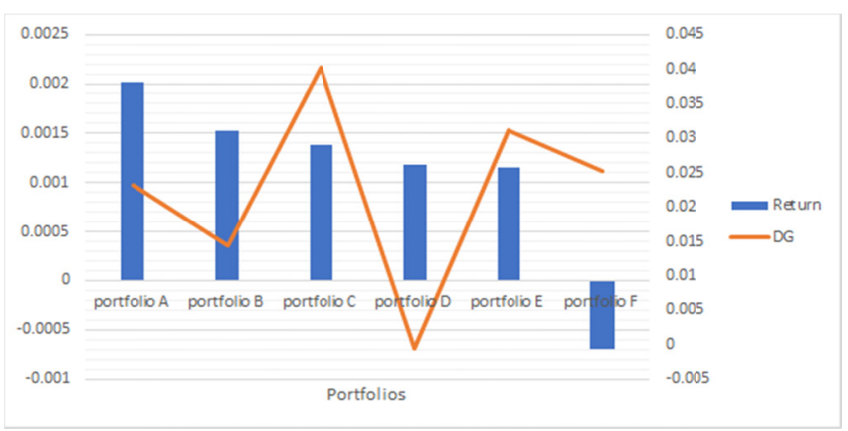

Figure 8. Portfolio returns and dividend growth, 2015-2016. 
The above graph presents an inverse relationship between portfolio returns and dividend growth. The contrast is clearly demonstrated by portfolios B and D, suggesting that higher portfolio returns tend to have lower dividend growth.

\subsection{Further Analysis}

Table 2 shows the output of the regression analysis, indicating a correlation coefficient $\left(R^{2}\right)$ of 0.4 , which means a low explanatory power of prediction. Figure 9 shows the predictive trend with a strong correlation and positive slope. The coefficient of the independent variable, in this case market return, is 0.82 , a standard error of 0.067 , and intercept of 0.00048 .

Table 2. Regression statistics of market return

\begin{tabular}{|c|c|c|c|c|c|}
\hline \multicolumn{6}{|c|}{ Regression Statistics } \\
\hline Multiple R & \multicolumn{5}{|l|}{0.648004864} \\
\hline $\mathrm{R}^{\wedge} 2$ & \multicolumn{5}{|l|}{0.421207313} \\
\hline $\mathrm{R}^{\wedge} 2$ Adjust & \multicolumn{5}{|l|}{0.41839764} \\
\hline Error & \multicolumn{5}{|l|}{0.018523097} \\
\hline Observations & \multicolumn{5}{|l|}{208} \\
\hline \multicolumn{6}{|l|}{ ANOVA } \\
\hline & $\mathrm{df}$ & SS & MS & $\mathrm{F}$ & Significance $\mathrm{F}$ \\
\hline Regression & 1 & 0.051436013 & 0.51436013 & 149.913274 & 2.94632 \\
\hline Residual & 206 & 0.070679657 & 0.00034311 & & \\
\hline \multirow[t]{2}{*}{ Total } & 207 & 0.12211567 & & & \\
\hline & Coefficients & Standard Error & $\mathrm{t}$ Stat & P Value & \\
\hline Interception & 0.000487445 & 0.001285313 & 0.37924247 & 0.704898442 & \\
\hline Return RM & 0.923135108 & 0.067228138 & 12.2439076 & 2.94632 & \\
\hline
\end{tabular}

Table 3 Shows associations of the proxies with respect to returns for each portfolio, indicating weak correlations according to the $R^{2}$ values. The table shows the results according to the rounds, depicting the effect of including variables in the model. The aggregate stock return is explained by including the beta value at the end of round 2 . The parameter values are DG, EPS, and beta. None of the covariates were significantly different from zero at 0.05 , as was observed by the simple regression analysis (see above). The independent variables also had low explanatory power when performed together. The most-seen $R^{2}$ pattern was around $20 \%$, which led to further decreasing the adjusted $R^{2}$ when including beta values in the model.

Table 3. Rounds of portfolio regression

\begin{tabular}{|c|c|c|c|c|c|c|c|}
\hline ROUND & PORTFOLIOS & f-value & DG t-value & EPS T-value & BETA-value & R2 & R2 Ad]usted \\
\hline & A & 0.39 & 0.84 & 0.17 & & 0.05 & -0.09 \\
\hline & A & 0.94 & 1.27 & -0.28 & -1.42 & 0.2 & -0.012 \\
\hline & $B$ & 0.3 & 0.68 & -0.05 & & 0.05 & -0.11 \\
\hline & $B$ & 0.55 & 0.85 & -0.66 & -1.08 & 0.13 & -0.01 \\
\hline & c & 16 & 1.25 & -1.24 & & 0.21 & 0.08 \\
\hline & c & 1.09 & 1.21 & -1.02 & 0.53 & 0.22 & 0.01 \\
\hline & $D$ & 1.71 & -1.79 & -0.01 & & 0.22 & 0.09 \\
\hline & $D$ & 1.06 & -1.66 & -0.01 & -0.18 & 0.22 & 0.012 \\
\hline & E & 0.38 & -0.87 & 0.17 & & 0.05 & -0.09 \\
\hline & E & 0.24 & -0.73 & 0.07 & 0.15 & 0.05 & -0.19 \\
\hline & $F$ & 1.31 & -0.33 & 1.29 & & 0.1795 & 0.4 \\
\hline 2 & $F$ & 1.06 & 0.2 & 15 & -0.8 & 0.22 & 0.0129 \\
\hline
\end{tabular}

Portfolio had has the smallest $p$ value of 0.07 . This shows that there was no significance in the test results. Only for Portfolio $\mathrm{F}$ did the correlation coefficient start to increase with $R^{2}$ adjusted from 0.0179 to 0.4 , denoting a substantial change in the aggregate explanatory power of proxies when adding the beta value.

None of the portfolios indicated that the covariates in the study period from 2013 to 2016 can be used to explain the stock return and no association exists between the variables and expected return. Also, the $p$ values that are not shown in the tables were not significant as none of them were less than $5 \%$, indicating a high probability of results showing coefficients close to zero. 
When multiple regression analysis was run with the summary portfolio, including all the explanatory proxies, the correlation coefficients increased only with dividend growth. The $p$ values were not as high as expected (Table 2). With an $R^{2}$ of 0.07 and $R^{2}$ of -0.08 , the model did not explain the correlation between EPS and dividend growth. When including all variables, a positive change occurred in $R^{2}$ but the $p$ value of the model was greater than the significance level, indicating the impossibility of rejecting the null hypothesis. The only proxy with a high $t$ was dividend growth, with an individual value of 0.67 (Table 4).

Table 4. Rounds of complete portfolio regression

\begin{tabular}{r|r|r|r|r|r|r|r|} 
ROUND & PORTFOLIOS & f-value & DG t-value & EPS T-value & BETA-value & R2 & R2 Adjusted \\
\hline 1 & ALL & 0.5 & 0.67 & -0.85 & & 0.07 & -0.077 \\
\hline 2 & ALL & 0.35 & 0.66 & -0.7 & -0.36 & 0.08 & -0.16 \\
\hline & & & & & & & \\
\hline
\end{tabular}

\section{Conclusions \& Future Research}

This research aimed to find explanatory power for some of the indicators selected from the main factors used to predict stock return. The factors that most of previous literature used in order to predict future stock returns were company performance, investor expectation, and investment risk. This study only used fundamental analysis; for this reason, the proxy of investor expectation was separated, as this was used to measure trends in technical analysis.

According to the test results, all the three proxies used in this research exhibited a weak explanatory power of stock return. The $p$ values on the portfolios were not significantly strong enough to reject the null hypothesis. From the literature review, we found that dividends have a weak power to predict returns over a particular time period. A number of reviewed studies found a negative relationship between dividends and stock return. According to Kothari and Shanken (1992), the investment in future projects at the expense of dividends yields may label this indicator as a weak proxy for stock return. As they argued, dividends are sacrificed to reinvest profits for new projects. However, in this research, when running the model with separate portfolios, the dividend growth became a stronger aggregate value for return variation. When executing the model with the complete portfolio and two other variables, the dividend growth became an important covariate in increasing the aggregate predicting power. To some degree, all the independent variables tested in this paper became relevant for measuring the prediction of return for the sample companies, even though the predicting power was very low. The results provide important information to evaluate the efficiency of the market, implying that all the variables contribute an important proportion for prediction. As mentioned before, our research covered large U.K. companies with no discriminatory focus on dividend policies, industrial sectors, or business culture, which should differ and affect results analysis.

With the data description, we assumed that the correlation was moderately positive as some of the proxies seemed fit to explain the prediction model. Beta values were more consistent with the data scatter plot and when running simple regression analysis. However, the correlation index showed a weak variable relationship with respect to returns. The $p$ values were not significant in the correlation index and the coefficients were small, particularly for earnings per share.

This study raises important questions about the nature of the role that some of the factors play in predicting stock return; however, the methodology suffers some important limitations. The observations were reduced to only four years of dividend and earnings announcements using the quarterly period data.

\section{References}

Ang, A., \& Bekaert, G. (2007). Stock Return Predictability: Is It There? The Review of Financial Studies, 20(3), 651-707. https://doi.org/10.1093/rfs/hhl021

Anhar, M. (2015). Indicators of Company Performance, Investors' Expectation and Investment Risk in Predicting Stock Return at Indonesia Stock Exchange. Journal of Resource Development and Planning, 5, 41-51.

Avramov \& Chordia. (2006). Predicting Stock Returns. Journal of Financial Economics, 82(2), 387-415. https://doi.org/10.1016/j.jfineco.2005.07.014

Basu, S. (1975). The Information Content of Price-Earnings Ratios. Financial Management, 4(2), 53-64. 
https://doi.org/10.2307/3665200

Bekiros, S., \& Gupta, R. (2015). Predicting Stock Returns and Volatility Using Consumption-Aggregate Wealth Ratios: A Nonlinear Approach. Economics Letters, 131, 83-85. https://doi.org/10.1016/j.econlet.2015.03.019

Besley, S., \& Brigham, E. S. (2006). Essentials of Managerial Finance (11th ed.). Oak Brook: The Dryden Press.

Bloomberg. (2018). Data derived from 'Monthly Data on 10 Years U.K. Yield'. Available at Bloomberg.

Campbell, J. Y., \& Yogo, M. (2006). Efficient Tests of Stock Return Predictability. Journal of Financial Economics, 81(1), 27-60. https://doi.org/10.1016/j.jfineco.2005.05.008

Choudhary, K., \& Choudhary, S. (2010). Testing Capital Asset Pricing Model: Empirical Evidences from Indian Equity Market. Eurasian Journal of Business and Economics, 3(6), 127-138.

Detzel, A., \& Strauss, J. (2017). Combination Return Forecasts and Portfolio Allocation with the Cross-Section of Book-to-Market Ratios. Review Of Finance, 22(5), 1949-1973. https://doi.org/10.1093/rof/rfx035

Enders, W., \& Pascalau, R. (2015). Pretesting For Multi-Step-Ahead Exchange Rate Forecasts With STAR $\begin{array}{lllll}\text { Models. International Journal of } & \text { Forecasting, } & 31(2), & 473-487 .\end{array}$ https://doi.org/10.1016/j.ijforecast.2014.12.003

Fama, E. F. (1990). Stock Returns, Expected Returns, and Real Activity. Journal of Finance, 45(4), 1089-1108. https://doi.org/10.2307/2328716

Fama, E. F. (1991). Efficient Capital Markets: II. The Journal of Finance, 46(5), 1575-1617. https://doi.org/10.2307/2328565

Fama, E. F., \& French, K. R. (1988). Dividend Yields and Expected Stock Returns. Journal of Financial Economics, 22(1), 3-25. https://doi.org/10.1016/0304-405X(88)90020-7

Fama, E. F., \& French, K. R. (1992). The Cross-Section of Expected Stock Returns. Journal of Finance, 47(2), 427. https://doi.org/10.1111/j.1540-6261.1992.tb04398.x

Fama, E. F., \& French, K. R. (2004). The Capital Asset Pricing Model: Theory and evidence. Journal of Economic Perspectives, 18(3), 25-46. https://doi.org/10.1257/0895330042162430

Fama, E. F., \& Macbeth, J. (1973). Risk, Return, and Equilibrium: Empirical Tests. Journal of Political Economy, 81(3), 607-636. http://dx.doi.org/10.1086/260061

Gong, J., \& Sun, S. (2009). A New Approach of Stock Price Trend Prediction Based on Logistic Regression Model. Proceedings of International Conference on New Trends in Information and Service Science, 1366-1371.

Gordon, M. J. (1962). The Savings, Investment and Valuation of the Corporation. The Review of Economics and Statistics, (44), 37-51. http://dx.doi.org/10.2307/1926621

Hou, K., Xue, C., \& Zhang, L. (2017). Replicating Anomalies, NBER Working paper 23394. https://doi.org/10.3386/w23394

Kothari, S. P., \& Shanken, J. (1992). Stock Return Variation and Expected Dividends: A Time-Series and Cross-Sectional Analysis. Journal of Financial Economics, 31(2), 177-210. https://doi.org/10.1016/0304-405X(92)90003-G

Lean, H., \& Smyth, R. (2015). Testing For Weak-Form Efficiency of Crude Palm Oil Spot and Future Markets: New Evidence from A Garch Unit Root Test With Multiple Structural Breaks. Applied Economics, 1-12. https://doi.org/10.1080/00036846.2014.1002905

Lintner, J. (1965). The Valuation of Risk Assets and the Selection of Risky Investments in Stock Portfolios and Capital Budgets. The Review of Economics and Statistics, 47(1), 13-37. https://doi.org/10.2307/1924119

Miller, M., \& Scholes, J. (1972). Rates of Return in Relation to Risk: A Reexamination of Some Recent Findings. In Michael C. Jensen (Ed.), Studies in the Theory of Capital Markets (pp. 47-78.). New York: Praeger.

Murphy, J., \& Murphy, J. (1999). Technical Analysis of the Financial Markets. New York Institute of Finance.

Pietrovito, F. (2016). Do Price-Earnings Ratios Explain Investment Decisions Better Than Tobin's Q? Evidence From German Firm-Level Data. Applied Economics, 1-13. https://doi.org/10.1080/00036846.2015.1137547

Setiono, B., \& Strong, N. (1998). Predicting Stock Returns Using Financial Statement Information. Journal of Business Finance \& Accounting, 25(5-6), 631-657. https://doi.org/10.1016/0165-4101(92)90025-W 
Sharpe, W. (1964). Capital Asset Prices: A Theory of Market Equilibrium under Conditions of Risk. Journal of Finance, 19(3), 425-442. https://doi.org/10.2307/2977928

Tobin, J. (1969). A General Equilibrium Approach to Monetary Theory. Journal of Money, Credit and Banking, 1(1), 15-29. https://doi.org/10.2307/1991374

Wu, Z. (2014). REITs: Capital Structure. Public Real Estate Markets and Investments, Chapter 13. Oxford University Press.

Xing, Y., Zhang, X., \& Zhao, R. (2010). What Does the Individual Option Volatility Smirk Tell Us About Future Equity Returns? Journal of Finance Quantitative Analysis, 45, 641-662. https://doi.org/10.1017/S0022109010000220

Zhou, P., \& Ruland, W. (2006). Dividend Payout and Future Earnings Growth. Financial Analysts Journal, 62(3). https://doi.org/10.2469/faj.v62.n3.4157

\section{Copyrights}

Copyright for this article is retained by the author(s), with first publication rights granted to the journal.

This is an open-access article distributed under the terms and conditions of the Creative Commons Attribution license (http://creativecommons.org/licenses/by/4.0/). 